\section{Design as a factor in the study of visual numerousness*}

\author{
DONALD GRANBERG \\ University of Missouri, Columbia, Mo. 65201
}

Ss estimated the number of black circles in three contextual conditions: $0 \mathrm{X}$ (no white circles), 4X (four times as many white as black circles), and 16X (16 times as many white as black circles); they further estimated the number of black circles under two designs: independent and related samples. For independent samples, estimates were significantly greater for the $0 \mathrm{X}$ than for the $4 \mathrm{X}$ and $16 \mathrm{X}$ conditions, while the latter two did not differ. For the related sample, the $0 \mathrm{X}$ and $4 \mathrm{X}$ produced higher estimates than the $16 \mathrm{X}$, while the former two did not differ.

A recent paper reported variations in estimates of numerousness as a function of the presence of additional stimuli which were not to be included in the estimates (Granberg \& Aboud, 1969). As the number of unfilled circles increased, the estimates of the number of filled circles tended to decrease. Although four conditions were used, most of the explained variance occurred because of the difference between the extreme conditions, the $0 \mathrm{X}$ condition with only to-be-counted elements, and the $4 \mathrm{X}$ condition with four times as many contextual (not to be estimated) as focal items.

The previous study used an independent sample design in which $\mathrm{Ss}$ participated in only one of the four conditions, $0 \mathrm{X}, 1 \mathrm{X}, 2 \mathrm{X}$, or $4 \mathrm{X}$. Also, the results of Granberg and Aboud were somewhat incompatible with earlier reports (Bevan, Maier, \& Helson, 1963; Bevan \& Turner, 1964). This paper reports an experiment which was designed to extend the study of contextual effects in estimates of visual numerousness. The $0 \mathrm{X}$ and $4 \mathrm{X}$ conditions were retained, but an additional condition (16X) was included as an extension. Also, the experiment was performed under two different designs using independent samples, as in the earlier study, and a related sample in which $S s$ gave estimates under all experimentally varied contextual conditions. The prediction was that estimates would vary as a function of the context in the manner $0 \mathrm{X}>4 \mathrm{X}>16 \mathrm{X}$ in both designs.

\section{SUBJECTS}

One hundred and twenty Ss from an introductory sociology course participated in the experiment. Sixty-three, 38 women and 25 men, were in the independent samples design. Twenty-one Ss were assigned randomly to each of three

*Gail Corrigan. Robert Fischer, Bill Hayes, and Jim Worstell assisted in this project. two designs. experimental conditions. The sex ratio was approximately the same for the three conditions. Fifty-seven Ss, 42 women and 15 men, participated in the related sample design.

\section{STIMULUS MATERIALS}

Twenty-one slides, seven for each of three contextual conditions, pictured small black and white circles on a large gray circle. The actual number of black circles varied by 2 between 24 and 36 . The white circles comprised the background variable and were none (0X), 4 times as many white as black circles $(4 \mathrm{X})$, or 16 times as many white as black circles $(16 \mathrm{X})$. In the 16X condition, the large gray circle was completely filled with 36 black circles and 576 white circles.
PROCEDURE

The Ss participated in small groups of three to five and made their estimates privately by writing them on a sheet provided. They were seated about $10 \mathrm{ft}$ from a screen on which the slides were shown in a semidarkened room. The instructions were the same for all conditions of both designs and were as follows: "This study involves a series of estimates of numbers with relatively short exposure times. I am going to present a series of slides on the screen. On each slide will be a number of black circles. No slide will have less than 10 or more than 50 black circles. Make your estimate without counting or trying to count them, as the time allotted to each is not sufficient for counting. All you have to do is take a good look at the picture and then make your guess as to the number of black circles."

The Ss in the related sample design were then presented 21 slides in random order. These 57 people thus made estimates of the $0 \mathrm{X}, 4 \mathrm{X}$, and $16 \mathrm{X}$ slides mixed together in a haphazard order. Ss in the independent samples design were presented only the seven slides appropriate for their experimental condition: $0 \mathrm{X}, 4 \mathrm{X}$, or $16 \mathrm{X}$. The random order in which the seven slides were presented was the same for all people in these three conditions.

The slides were projected by a

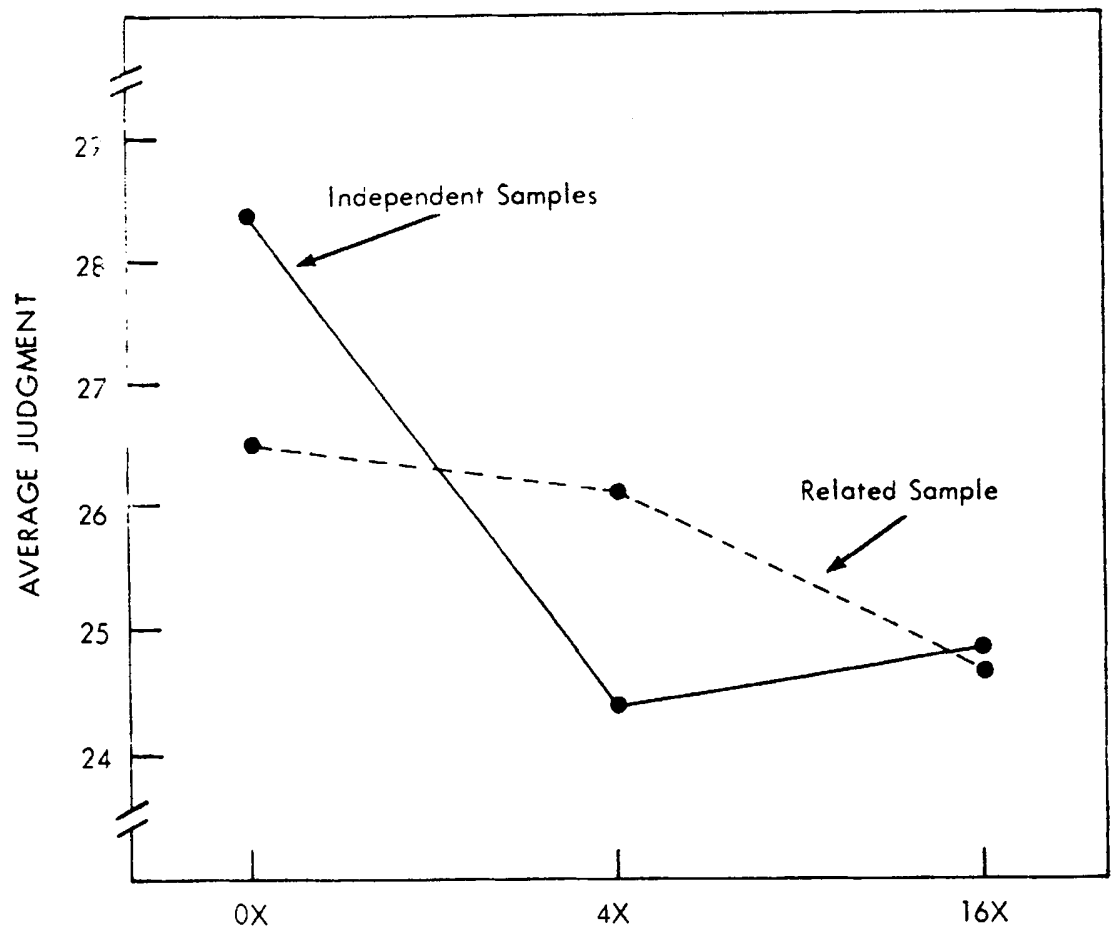

CONTEXTUAL CONDITION

Fig. 1. Mean judgments of numerousness in three contextual conditions and 
Table 1

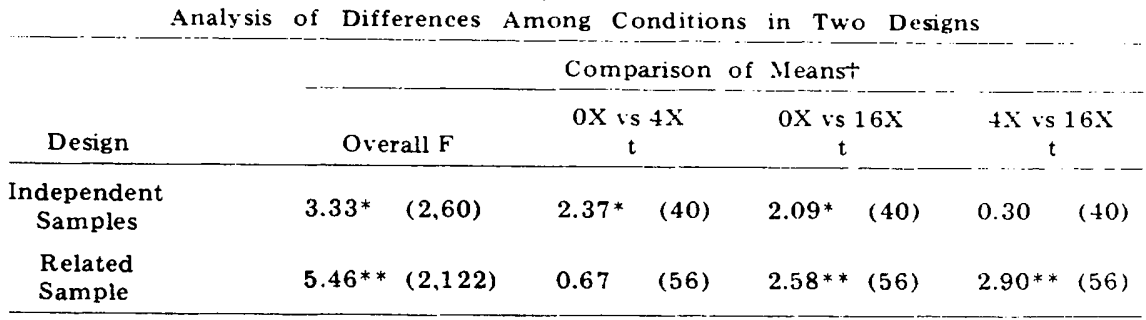

+The degrees of freedom are in parentheses following the $F$ and $t$ lalues (IIIner. 1962. Pp. 5 3, 113).

$* p<.05, * * p<.01$

Kodak Carousel projector, and the exposure time was $3 \mathrm{sec}$ for all presentations with an interval of $7 \mathrm{sec}$ between slides.

RESULTS AND DISCUSSION

Generally, estimates showed a correspondence with variations in the actual number in all conditions. Another feature of the estimates was consistent underestimating of the actual number of black circles. However, since the main interest was in contextual conditions, estimates were combined so that each person in the independent samples condition received a score derived by simply combining his seven judgments. People in the related sample design received three such scores: one for their seven $0 \mathrm{X}$ estimates, another for their $4 \mathrm{X}$ estimates, and a third for their estimates of the $16 \mathrm{X}$ slides.

Figure 1 shows the average of these estimates for the three stimulus conditions and the two designs. Taken as a whole, there is support for the predicted linear relationship. However, there are some curious deviations.

The results of analyses of variance and $t$ tests are given in Table 1 . Both designs yielded a significant overall $\mathrm{F}$ ratio. However, in the case of the independent samples, the $0 X$ condition differs reliably from both the $4 \mathrm{X}$ and the $16 \mathrm{X}$ conditions, while the $4 \mathrm{X}$ and $16 \mathrm{X}$ conditions do not differ reliably from one another. On the other hand, for the people in the related sample, estimates of the $0 \mathrm{X}$ slides were significantly greater than those of $16 \mathrm{X}$ slides but not those of the $4 \mathrm{X}$ slides. Also, the $4 \mathrm{X}$ slides were judged as reliably greater than the $16 \mathrm{X}$ slides by the related sample. Thus, there was some divergence from the simple $0 \mathrm{X}>4 \mathrm{X}>16 \mathrm{X}$ (predicted) relationship in each design.

The significant difference between the $0 \mathrm{X}$ and $4 \mathrm{X}$ conditions in the independent design may be considered a successful replication of the main finding of Granberg \& Aboud (1969).
However, the fact that the $16 \mathrm{X}$ condition actually resulted in higher (though not significantly so) estimates than the $4 \mathrm{X}$ condition in the independent design constitutes strong evidence that this contextual effect is something other than a simple linear function.

Also, the results indicate that for the related sample, the differences in estimates of the $0 \mathrm{X}$ and $4 \mathrm{X}$ slides are within the range of random variation. This indicates that the context effect reported by Granberg and Aboud is limited to some extent to the design they used (independent conditions).

The extension in the present study was to include the $16 \mathrm{X}$ condition and the related sample. In the related sample, judgments of the $4 \mathrm{X}$ slides did not differ from those of the $0 \mathrm{X}$ but were judged as significantly greater than the $16 \mathrm{X}$ slides. This may indicate that when people are judging the entire set of stimuli, as in the related sample, a rather substantial context is required in order to produce an effect on estimates.

\section{REFERENCES}

BEVAN, W., MAIER, R., \& HELSON,H. The influence of context upon the estimate of number. American Journal of Psychology, 1963, 76, 464-469.

BEVAN, W.. \& TURNER, E. Assimilation and contrast in the estimation of number. Journal of Experimental Psychology, $1964,67,458-462$.

GR ANBERG, D., \& ABOUD, J. A contextual effect in judgments of visual numerousness. American Journal of Psychology, 1969, 82, 221-227.

WINER, B. Statistical principles in experimental design. New York: McGraw-Hill, 1962. 